\title{
A HUMANIZAÇÃO HOSPITALAR: UM OLHAR SOBRE O PROJETO "LEITURA: ASAS \\ DA LIBERDADE" NA SANTA CASA DE CARIDADE EM FORMIGA-MG
}

\author{
Tânia de Fátima Gontijo Fonseca \\ Especialista em Administração de Sistema de Informação \\ Professora do Curso de Biblioteconomia do UNIFOR-MG \\ e-mail: taniagontijo@gmail.com \\ Paulo Henrique G. Fonseca2 \\ Graduando em Biblioteconomia do UNIFOR-MG, \\ e-mail: paulohenriquegf@hotmail.com
}

\begin{abstract}
RESUMO
Relato de experiência que mostra a biblioteca como instituição transformadora da sociedade, buscando novos serviços, sempre promovendo a construção e o fortalecimento da cidadania, utilizando-se da cultura e da informação. "Leitura: Asas da Liberdade" trata-se de um projeto de ação social que, com dinamismo e criatividade, promove a cultura e incentiva o gosto pela leitura, proporcionando entretenimento por meio de técnicas biblioterapêuticas em hospitais. Apresenta sua trajetória na Santa Casa de Caridade na cidade de Formiga-MG. Este artigo tem por objetivo apresentar a leitura como instrumento de humanização em hospitais.
\end{abstract}

Palavras-Chave: Leitura. Biblioterapia. Universidade. Humanização. Hospitalização.

\section{THE HOSPITAL HUMANIZATION: A LOOK AT THE PROJECT "READING: WING OF THE FREEDOM" IN THE SANTA CASA DE CARIDADE IN FORMIGA-MG}

\begin{abstract}
Experience report that shows the library as transforming institution of the society, searching new services, always promoting the construction and the reinforcement of the citizenship, using the culture and the information. "Reading: Wing of the Freedom" is about a project of social action that, with dynamism and creativity, promo- tes the culture and stimulates the taste for the reading, providing entertainment through library-therapeutc techniques in hospitals. It presents its trajectory in the Santa Casa de Caridade in the city of Formiga-MG. This article aims to present the reading as instrument of humanização in hospitals.
\end{abstract}

Keywords: Reading. Library-therapy. University. Humanization. Hospitalization.

\section{INTRODUÇÃO}

A hospitalização é um acontecimento que pode gerar em todos, sentimentos como medo, sensação de culpa e resultar em reações inadequadas durante a internação, pois esta situação está sempre associada à dor, ao sofrimento e à morte. Adams (1999, p. 10) tão bem traduz este evento:

Ser internado em um hospital é uma situação de extrema vulnerabilidade. Os pacientes e suas famílias foram (sem aviso prévio) colocados em um contexto onde o medo e a confusão deixam a maior parte das pessoas tensas e ansiosas. Vidas são desestruturadas ou mudadas para sempre. 
Entende-se que a hospitalização gera no indivíduo efeitos que podem prejudicar o seu desenvolvimento psicológico e emocional. A realidade hospitalar pode ser nova e desconhecida, situação essa que dificulta o ajustamento neste ambiente e nesse novo clima de suspense e desinformação, geramse fantasias e temores.

De acordo com Chiattone (2003), assim como ocorre com adultos que estão hospitalizados, que enfrentam ansiedades e temores devido às suas doenças, e necessitam de um tratamento humanizado para que possam manter o equilíbrio psico-físico, a criança que adoece e precisa de internação, pode alterar a concepção de si mesma e de sua identidade. Isso devido à ruptura estabelecida com o seu cotidiano, pela hospitalização. Assim, ela necessita, ainda mais, de atenção especial para que se minimize este tipo de sofrimento, uma vez que ainda não tem amadurecimento psíquico para elaborar, adequadamente, todos os seus medos e angústias.

Observa-se que os hospitais, na sua maioria, não oferecem nenhuma atividade de lazer aos pacientes. Dessa maneira, ficam horas e horas inertes no leito, olhando para o teto, mergulhados na dor, em pensamentos e preocupações.

Neste contexto, Oliveira (2004) descreve a importância da presença de um acompanhante durante o período de hospitalização da criança, tendo como demonstração os resultados das reações físicas e emocionais apresentadas por ela.

Partindo deste pressuposto, as crianças hospitalizadas sem acompanhamento manifestam mais reações físicas (inapetência, taquicardia, insônia, vômito) e emocionais (irritabilidade e agressividade) do que as crianças acompanhadas.

Acreditando que os efeitos da hospitalização são realmente prejudiciais à integridade psicológica da criança, o uso do lúdico pode transmitir informações e esclarecer dúvidas e fantasias, melhorando a qualidade de vida neste período. A palavra brincar origina-se do latim vinculum, que significa união, laço, sendo uma atividade fundamental entre as crianças. Nas enfermarias pediátricas, onde há necessidade de integração entre os profissionais de saúde, a criança e sua família, o ato de brincar é uma forma de fortalecer estes vínculos tão necessários ao bom andamento do tratamento. Ao alterar o ambiente hospitalar, aproximando-o do seu, verifica-se, então, um efeito positivo.

Vários autores consideram o uso do lúdico - por exemplo: o brincar, o uso da fantasia, histórias, entre outros - como a melhor escolha para a intervenção psicológica com crianças hospitalizadas. Adams (1999, p.11) conclui: "As histórias tornam-se instrumento poderoso em uma visita ao hospital[...] estabelece uma confiança, pois ninguém se sente em casa ou quer estar ali[...]."

A iniciativa de se criar um projeto de leitura, de forma inusitada e lúdica, para pacientes internados em um hospital, originou-se também da experiência de acompanhar, de perto, a dor e o sofrimento de pacientes da família durante o processo de hospitalização. Pacientes crianças, jovens, adultos e idosos sofrem, muitas vezes em silêncio, recolhidos na sua dor, angústia, desespero e incerteza diante da doença. 
O convívio com essa realidade nos fez repensar a necessidade de fazer algo que amenizasse a dor provocada pela hospitalização, seria, então, o projeto "Leitura: Asas da Liberdade".

\section{MATERIAS E MÉTODOS}

Este estudo classifica-se como uma pesquisa-ação, que, segundo Lima (2008, p.37), corresponde a um:

Método que tem por característica principal, simultaneamente, o exercício da pesquisa à ação participante sobre a realidade, objeto da investigação. Parte do pressuposto de que o(s) pesquisador(es) e os atores envolvidos no processo investigatório são agentes complementares na medida em que são co-responsáveis pelas etapas que caracterizam a concepção do projeto de pesquisa, sua execução e a elaboração dos resultados alcançados.

Mediante o enunciado acima, torna-se relevante ressaltar também Severino (2007, p. 120), "que afirma que a pesquisa ação, além de compreender, visa intervir na situação com vista a modificá-las. O conhecimento articula-se a uma finalidade intencional de alteração da situação pesquisada.

Com base numa metodologia crítico-reflexiva, utilizou-se para a elaboração deste relato de experiência a técnica de observação por parte do professor coordena- dor e dos estagiários, considerando-se um estudo de intervenção biblioterápica, na Santa Casa de Formiga-MG. Paralela à observação, optou-se por uma abordagem qualitativa que, conforme Minayo (1994, p.212):

A pesquisa qualitativa responde a questões muito particulares, onde o universo de significados, motivos, aspirações, crenças, valores e atitudes, corresponde a um espaço mais profundo das relações, dos processos e dos fenômenos que são podem ser reduzidos à operacionalização de variáveis.

É oportuno citar Lima (2008), que enfatiza a importância do relacionamento íntimo que se estabelece entre o pesquisador e o que é estudado, situação possibilitada pelas frequentes visitas ao hospital.

É um estudo exploratório, visto por Lakatos e Marconi (1991),

Como o primeiro passo de todo o trabalho científico. Este tipo de pesquisa tem por finalidade definir os objetivos ou formular as hipóteses de uma pesquisa ou, ainda, descobrir um novo enfoque para o estudo que se pretende realizar. Pode-se dizer que a pesquisa exploratória tem como objetivo principal o aprimoramento de ideias ou a descoberta de intuições.

De acordo com Gil (1991), o estudo de caso é caracterizado pelo estudo exaustivo e em profundidade, de forma a permitir um conhecimento amplo e específico do mesmo. A técnica de pesquisa adotada para a coleta de dados foi a observação participante, que de acordo com Lakatos e Marconi (1991), consiste na participação real do observador com a comunidade ou grupo, tornando-se um membro desse grupo investigado, o que lhe permite vivenciar a realidade observada, relatando, assim, todas as atividades realizadas e as reações dos pacientes, por meio de diários de campos semanais, após cada visita ao hospital.

O diário de campo ajuda na progressão da pesquisa para uma posterior análise por ser uma forma de anotação pessoal desenvolvida a partir da realidade e das vivências percebidas nas atividades teórico e 
práticas. Segundo Minayo (1993, p. 10), nele,

[...] constam todas as informações que não sejam o registro das entrevistas formais. Ou seja, observações sobre conversas informais, comportamentos, cerimoniais, festas, instituições, gestos, expressões que digam respeito ao tema pesquisado. Fala, comportamentos, hábitos, usos e costumes, celebrações e instituições compõem o quadro das representações sociais.

É realizada uma análise destes relatórios, identificando-se o alcance dos obje- tivos e as impressões dos sujeitos, por meio de depoimentos deixados em cadernos próprios. Torna-se importante salientar que se trata de depoimentos de pacientes e/ ou acompanhantes, enfermeiros, funcionários do hospital e estagiários do projeto. Por fim, é importante salientar que o relato oral dos estagiários, a cada visita foi de suma importância para se chegar ao desejo e à decisão da realização deste estudo.

\section{ASPECTOS GERAIS DO PROJETO "LEITURA: ASAS DA LIBERDADE"}

O projeto "Leitura: Asas da Liberdade" é um projeto de extensão criado pelos professores do Curso de Biblioteconomia do UNIFOR-MG . O público atendido é diversificado, sem limites de faixa etária, situação econômica, social e cultural.

O projeto se iniciou em maio de 2002, com o desejo de melhorar a qualidade de vida - através da leitura - de pessoas diferenciadas na comunidade. Pessoas estas que se encontram afastadas do lar ou marginalizadas por seu comportamento ou desajustamento social. "Asas da Liberdade" é poderoso veículo de informação, levando o indivíduo a aprender a "ler" o mundo de forma lúdica e prazerosa. Utiliza como ferramenta principal a leitura, no desenvolvimento da biblioterapia no processo de humanização.

Trata-se de um projeto de ação comunitária que, além de incentivar a leitura, procura aplicar a biblioterapia - leitura com propósito terapêutico, a fim de ajudar na recuperação física, psicológica e moral de pessoas, promovendo assim, um processo de humanização em hospitais, creches, escolas, instituições com portadores de necessidades educacionais especiais e presídios da cidade.

Por ser um projeto de extensão universitária, busca favorecer a melhoria da qualidade de ensino, inserindo acadêmicos bolsistas nas comunidades periféricas, através de estágios, na perspectiva de, juntamente com esses, identificar os problemas existentes e procurar amenizá-los, utilizando-se da literatura aliada à biblioterapia. O estágio acontece de fevereiro a novembro de cada ano e apresenta os seguintes momentos: treinamento/capacitação, visitas, avaliação.

O "Asas da Liberdade" é composto por uma equipe de 1 professora coordenadora e 5 estagiários, onde os mesmos desenvolvem atividades lúdicas, sempre procurando trabalhar as emoções do espectador. De segunda a sexta-feira, em horários pré-estabelecidos, os estagiários realizam visitas de acordo com um cronograma anual, desenvolvendo diversas atividades.

Num primeiro momento, optou-se por implantações de caixas-estantes - caixa de madeira, tipo estante, onde é colocado o material bibliográfico especialmente selecionado para o local em que irá 
servir. Comporta aproximadamente, 100 livros e tem rodinhas para se movimentar - mas, em face do aumento de demanda, houve necessidade de adaptar o projeto, desenvolvendo atividades inovadoras. Dentre elas, pode-se citar:

a) contação de histórias: utilizando os recursos lúdicos, como, cineminha, álbum seriado, fantoches, xilogravuras, teatro, tapetes de histórias, dentre outros. Distribuição de brindes confeccionados pela equipe, após a contação;

b) oficinas de reflexão: palestras e debates sobre temas relacionados à auto-estima;

c) oficinas de criatividade, como pintura, desenho, pintura de rosto, dobradura, colagem, etc;

d) intervenção oral e leitura mediada, distribuição de flores e mensagens, no caso de hospitais;

e) observação de hábitos, costumes, tradições e crenças da comunidade.

Torna-se relevante mencionar Arnold Schoenberg apud Gardner (1997 p. 58), que completa, de maneira significativa, esse poder de observação e discriminação: "Procurar por si mesma, observar, comparar, definir, descrever, ponderar, testar, tirar conclusões e utiliza-las. habilidades que são constantemente renovadas e aumentadas a partir da profundidade do conhecimento que é entendido."

\subsection{Trajetória do projeto "Asas da Liberdade" na Santa Casa de Caridade de Formiga-MG}

Um estudante de Medicina dos Estados Unidos mudou, para sempre, o modo como muitos doentes são tratados em vários hospitais do mundo. Seu nome é Hunter Adams, mas ele é mais conhecido como Patch Adams. Onde os médicos viam apenas pacientes, Patch via pessoas. Ao prescrever remédios para curar as doenças, Patch Adams ministrava também boas doses de alegria.

Sua história foi contada no filme "Patch Adams - O amor é contagioso" (1998) que tem belas cenas que serviram para inspirar a idéia de um projeto a ser desenvolvido no hospital de Formiga-MG. Este filme tocou, profundamente, a professora da disciplina Usuários da Informação, do curso de Biblioteconomia do UNIFOR/MG.

Durante algum tempo, questionou-se: como o curso de Biblioteconomia poderia atuar com objetivo curativo em um hospital? Após várias alternativas e variáveis estudadas, optou-se, então, pela criação de um serviço de caixa-estante, na pediatria da Santa Casa.

Certos de estar fazendo algo de melhor pelos pacientes mirins da cidade, dirigiu-se até à direção do hospital para exposição dos propósitos e explicar o funcionamento da mesma. Já na primeira visita, nos foi passada a dificuldade em esterilizar o acervo desta caixa-estante, pois o hospital não dispunha de tecnologia para tal atividade, principalmente porque se tratava de livros. Triste e pensativa, retirou-se, pois sabia-se que dispúnhamos de um instrumento poderoso que era "a informação".

Depois de pensar muito, surge, então, outra idéia: "Se é impossível levar livros, levaremos histórias." Qual criança não gosta de histórias? Mas como levar histórias de uma maneira lúdica, 
mágica? Era preciso encontrar uma maneira que chamasse a atenção das crianças, as fizesse sonhar e se esquecer até mesmo da condição em que se encontravam.

Foi quando lembrou-se dos contos de fadas. Seria de praxe que, em todas as visitas ao hospital, os estagiários, estivessem devidamente caracterizados de acordo com os personagens das histórias, provocando o verdadeiro encantamento e magia nos corações e olhos dos pequenos pacientes.

Nova reunião foi realizada com a equipe da Santa Casa de Caridade. Após uma nova explanação sobre a nova proposta, ficou acertado que as visitas seriam às terças-feiras no período da tarde. A regularidade das visitas iria criar cumplicidade entre estagiários, pacientes e os profissionais da área da saúde, desenvolvendo relacionamento cooperativo entre os diferentes grupos profissionais da instituição hospitalar. Tendo como princípio a aceitação da criança, a caracterização, as rotinas prévias e a improvisação.

Inicia-se, assim, em maio de 2002, o projeto "Leitura: Asas da Liberdade", cujo nome exprime o compromisso, enquanto profissionais da informação, de libertar muitos usuários da ignorância, solidão e das doenças que lhes afligem, da ausência da família, da carência afetiva. Houve um momento, durante o embasamento teórico sobre a contação de história, em que deparou-se com a biblioterapia - utilização de materiais de leitura selecionados como coadjuvante terapêutico na medicina e na psiquiatria: a orientação na solução de problemas pessoais por meio de leitura dirigida e o tratamento do mal ajustado para promover sua recuperação à sociedade (MOOD; LIMPER, 1973 apud CALDIN, 2001) - e pode-se perceber que se estava trabalhando de forma intuitiva na escolha das histórias. Procurava-se levar histórias que administrassem sentimentos negativos, como medo, insegurança, dentre outros, e que as mesmas tivessem finais felizes. Mostrando assim, que é sempre possível encontrar saídas, construindo uma necessidade de flexibilização diante da doença.

A partir daí, a escolha da história passou a ser mais criteriosa e, após sua contação, uma intervenção biblioterápica era realizada, pois segundo Adams (1999), uma conversa relaxa e transforma o ambiente [...] é preciso ser bom ouvinte e compartilhar ternura. A biblioterapia faz uso de uma linguagem metafórica, que faz o indivíduo pensar livremente, projetar-se no outro, observando qualidades, sentimentos, desejos ou mesmo "detalhamentos" que ele desconhece ou recusa em si próprio.

[...] A história é importante alimento da imaginação. Permite auto-identificação (sic) favorecendo a aceitação de situações desagradáveis e ajuda a resol- ver conflitos, acenando com a esperança. Agrada a todos, de modo geral, sem distinção de idade, de classe social, de circunstância de vida. (COELHO, 2001, p. 7).

Esta reflexão de sentimentos é terapêutica, podendo ser a fonte para mudanças de comportamentos e moderação das emoções. Relação esta confirmada pelos inú- meros estudiosos desta linha de pesquisa, dentre eles Caldin (2002, p. 4), que diz [...] "observa-se que o fator emocional é levado em conta na luta contra as enfermidades e a humanização vem revolucionando os antigos métodos de tratamento".

Partindo deste pressuposto, utilizou-se das variadas técnicas de contação de histórias para conseguir o alívio da tensão diária causada por doenças, problemas pessoais e/ou psicológicos. Hoje, 
após oito anos de intenso trabalho, o projeto tornou-se parceiro na rotina hospitalar, visitando não apenas a pediatria, mas cada leito hospitalar. Isso se deve a pedido dos coordenadores e funcionários, que perceberam a eficácia do mesmo. Mais uma vez, Adams (1999) consegue sintetizar o valor destas visitas, afirmando que qualquer visita pode ser um remédio poderoso para paciente e visitante.

\section{TÉCNICAS UTILIZADAS NA CONTAÇÃO DE HISTÓRIAS EM HOSPITAIS}

Arte é tudo que comove, emociona, desenvolve a sensibilidade. É importante porque celebra os momentos da alma ou algum acontecimento trágico ou especial na sua trajetória.

Como toda arte, a de contar histórias também possui segredos e técnicas e tem como matéria-prima a palavra, privilégio do ser humano. Depende, naturalmente, de certa tendência inata, mas pode ser desenvolvida, cultivada, desde que se goste de crianças e se reconheça a importância da história para elas.

Pensar a ludicidade de forma complexa é adotar estratégias de intervenções pedagógicas que possibilitem não apenas oferecer e oportunizar momentos lúdicos, mas extrair sua essência, de maneira a permitir interpretação do valor que as pessoas atribuem a estes momentos.

É recomendável ser bastante criativo no uso de recursos materiais. Não se prender a certos padrões, mas variar, de acordo com o conteúdo da história a ser contada ou apresentada. Para Chiattone (2003, p. 56):

\footnotetext{
Brincando e conversando, as crianças conseguem exprimir seus medos, falar sobre a doença, sobre o tratamento, o hospital, a saudade da família, sobre a morte. Os acontecimentos e as condutas são elaborados, explicados exaustivamente, conseguindo-se quase sempre aliviar e esclarecer, além de trazer enorme alívio, dando condições a criança de agir por si na situação.
}

Algumas técnicas de contação são mais aceitas, ou melhor, mais eficazes quando se trata da pediatria, outras, quando se trata da área clinica, ou seja, nos leitos de adultos.

A música pode servir como um importante elemento no ambiente hospitalar, ao propiciar momentos alegres e descontraídos. Nas atividades de música, os pacientes podem tanto ouvir, quanto cantar, além de oferecer momentos de tranquilidade, tão necessária ao ambiente hospitalar.

Para crianças da pediatria, utiliza-se, com grande ocorrência, as xilogravuras, quadros de cenas das histórias, que são apresentados durante a narração. Realiza-se também a leitura de grandes livros, reescritos em cartolinas, por meio de desenhos, colagens, pinturas e, depois, encadernados. Teatro de fantoches é sempre bem-vindo. O baralho de histórias representa uma técnica interessante, que agrada dos pequeninos aos maiores por ser uma técnica diferenciada, podendo-se utilizá-la juntamente com a música.

A narrativa de histórias contadas ou simplesmente lidas deve ter uma duração média de 5 a 10 minutos para as crianças menores e de 15 a 20 minutos para as maiores. A repetição da história, se 
solicitada, deve ser sempre atendida. Outra história não deve ser iniciada sem intervalo. Uma conversa preparatória, que motive para a nova vivência, é muito bem-vinda. Qualquer pessoa que saiba ler adequadamente e goste de trabalhar com literatura e pessoas - crianças e adultos - pode e deve participar dessa experiência.

A partir da leitura, do uso de fantoches e outros brinquedos, pode surgir a oportunidade de dramatizar, atividade muito apreciada pelas crianças, e que permite vivenciar e elaborar situações difíceis do cotidiano hospitalar. Atividades artísticas com o uso de lápis de cor, tinta guache, canetas coloridas são formas ricas de ajudar os pacientes a minimizar as perdas de laços afetivos, facilitando a verbalização e a elaboração dos seus sentimentos, em decorrência de longos períodos de internação.

O uso da flanelogravura - quadro revestido de flanela ou feltro de cor lisa, sobre o qual se fazem aderir objetos ou figuras, fixadas ou removidas, segundo as cenas das histórias - pode ser uma boa opção para ilustrar uma história com vários assuntos e vários simbolismos.

A mediação de leitura deve ser sugerida aos pacientes de todas as idades, aos jovens e pais. É bom incluir essa ação cultural em situações cotidianas, em momentos transitórios ou livres da internação e do atendimento às pessoas nos hospitais. Quaknin (1996, p.152) ressalta a importância da terapia do diálogo mediado pelo livro e pela interpretação:

O diálogo biblioterapêutico não é o simples diálogo, mesmo bem sucedido, em que cada um fala e escuta em atitude de respeito mútuo. A particularidade do diálogo é a presença entre os parceiros do diálogo, de um texto, de um livro, de um objeto de arte, de um objeto simplesmente a ser comentado e interpretado. De fato, em todo diálogo há um referencial comum sobre o que se fala.

Portanto, a leitura mediada pelo prazer que traz e pela situação de intimidade e proximidade afetiva que possibilita, reconstitui a vitalidade. Assim pode-se falar, pensar e sonhar com coisas que não se referem apenas à situação geradora de tristeza.

As atividades de origami são muito bem aceitas, aliadas à contação como, por exemplo:

a) Borboletinha: levar o origami da borboleta. Começar a contar uma estória sobre uma borboleta que resolveu sair do seu jardim e conhecer a cidade, mas que estava se sentindo muito sozinha, encontrando poucas flores e nenhuma outra bor- boleta. Pedir às crianças que continuem a estória. Ensinar a elas a fazer o origami da borboleta. Cada origami será um novo amigo da borboletinha. Fazer também corte e colagem montando flores. Com a ajuda das crianças, o quarto se transformará num lindo jardim. Cantar com elas a música Borboletinha, acompanhando no violão ou no $\mathrm{CD}$;

b) Peixinho: trazer o origami do peixe e começar uma estória. "O pescador, o anel e o rei" de Bia Bedran. Ensinar a elas a fazer o origami do peixinho. Cantar a música do "Peixe Vivo".

Nos leitos adultos os estagiários, desenvolvem várias atividades de intervenção. As mais freqüentes são:

- acolhimento do paciente, contribuindo para a construção de uma análise reflexiva sobre sua 
trajetória no hospital;

- reflexão sistemática sobre o processo de adoecimento e formas subjetivas (dor, sofrimento) para enfrentamento deste processo;

- distribuição de mensagens de otimismo, fé, que, geralmente, tratam da aceitação e esperança diante da doença;

- distribuição de flores regadas à música com temas de espiritualidade, fé e alegria.

\section{RESULTADOS E DISCUSSÃO}

O trabalho desenvolvido na pediatria da Santa Casa de Caridade só comprova a frase do Dr. Patch Adams (1999, p. 20) [...] "os principais fatores para a saúde não estão nas últimas maravilhas tecnológicas, mas em coisas comuns como o amor, a compaixão, a amizade e a esperança."

Os estagiários encontram crianças tristes e chorosas e, após a intervenção oral, acompanhada de contação de história, o quadro muda de maneira visível: a criança esquece a dor física e se interage completamente com os estagiários, participando, ativamente, dos questionamentos biblioterápicos. Essa interação mediada pela leitura facilita a integração das crianças e de sua família com a equipe do projeto e do hospital, proporcionando também alívio de tensões e fomentando mudanças nas ações e reações das crianças. Dessa maneira, é significativo que se ajude os pequenos pacientes a integrar as emoções geradas pelo imaginário, a fim de torná-las amigas, geradoras de energia.

A criança mostra-se feliz com a presença dos personagens caracterizados, sente-se segura e confiante, a ponto de facilitar o trabalho de enfermeiros. "É reconfortante ver a alegria das crianças que chegam até você sem medo, acreditando que você está ali para ajudá-las, e não para "judiar" delas como em geral, vêem os enfermeiros - que você é quem as ajuda a abrir as portas da imaginação e também a ver além das letras e das figuras. O que perpassa no momento em que se media a leitura de uma história é uma sensação de bem-estar" - assim relatam os integrantes do projeto.

As mães e/ou acompanhantes geralmente se sentem gratos pela presença da equipe do projeto. Temos casos de mães enviarem cartas agradecendo pela mudança de humor e comportamento do paciente, após a visita de nossa equipe. Segundo elas, as crianças levam para casa, após a alta, o desejo de ler e pedem que os pais comprem livros ou leiam estórias para elas, quando ainda não sabem ler.

Temos relatos de jovens, adultos e idosos que agradecem aos estagiários os momentos tão agradáveis que passaram no hospital nos dias de visitas. Oportunizou-se a esses pacientes a vivência de momentos alegres, descontraídos e diverti- dos, contribuindo, significativamente, para o alívio da tensão do ambiente hospitalar.

Há casos constantes de demonstração de emoção de homens e mulheres, por meio de olhares, sorrisos e mesmo choro durante o recebimento de flores e mensagens. Neste evento, não se pode deixar 
de mencionar, mais uma vez, Pat Adams (1999, p. 50), pois, segundo ele, [...] "flores sempre ajudam a curar pessoas doentes."

A alegria de um senhor ao solicitar aos estagiários que os mesmos tocassem músicas sertanejas, e, mesmo acamado, cantou, emocionou imensamente a equipe do projeto." A música realmente proporciona um clima agradável, onde os senti- mentos podem ser compartilhados e questões relativas ao estado psicológico podem ser trabalhadas.

Enfim, todos os profissionais da Santa Casa aprovam a visita do projeto, relatam ser relevante para o aprendizado e humanização da atenção à saúde e confirmam alterações positivas no ambiente hospitalar.

\section{CONCLUSÃO}

A humanização pode ser descrita como a valorização do outro, respeitando-o como pessoa. Desta forma, o projeto "Leitura: Asas da Liberdade" é uma prova que o profissional da informação pode, através da leitura, desenvolver um trabalho de humanização de relevância, uma vez que se baseia não apenas em uma teoria que entende a contação de histórias como fator de transformação social, mas também em um conhecimento empírico. É certo que a contação de histórias e a caracterização de personagens é essencial em um hospital, pois ameniza muito o medo e a tensão do ambiente hospitalar.

A biblioterapia passa a ser uma nova oportunidade de atuação no campo de trabalho do bibliotecário. As atividades relacionadas a ela são ótimas para o desenvolvimento da criatividade, incentivo ao gosto pela leitura e pacificação das emoções.

O projeto, realmente, é um sucesso, devido às mudanças comportamentais causadas após as visitas. Percebemos a necessidade de desenvolvimento e pesquisa destas atividades, para levar a mensagem de humanização aos profissionais, acadêmicos e pacientes. Desenvolver esse projeto nos proporciona um novo olhar sobre outras formas de prestar cuidados e oportunidades de influenciar mentes para que, ao longo de suas existências, sejam pessoas mais felizes e saudáveis em seus pensamentos e hábitos de vida.

Cabe ao bibliotecário criar maneiras criativas, prazerosas e ir muito além da contação de história. Os pacientes clamam por solidariedade, por quem possa contribuir com o instrumento muito poderoso que é a leitura terapêutica. Enfim, "Leitura: Asas da Liberdade" é uma prova de que o profissional da informação pode, por meio da leitura, desenvolver um trabalho social de relevância, como é feita em todo projeto de ação comunitária. 


\section{REFERÊNCIAS}

ADAMS, P. Patch Adams: o amor é contagioso. Rio de Janeiro: Sextante, 1999.

CALDIN, C. F. Biblioterapia para crianças internadas no Hospital Universitário da UFSC: uma experiência. Revista de Biblioteconomia e Ciência da Informação, Florianópolis, n. 14, out. 2002.

CHIATTONE, H. B. C. A criança e a hospitalização. In: ANGERAMI-CAMON, V. A. (Org.). A psicologia no hospital. São Paulo: Thomson, 2003. Disponível em<http://susanaalamy.sites.uol.com.br/ psicopio_n6_38.pdf >. Acesso em: 27 fev. 2010.

COELHO, T. O que é ação cultural. São Paulo: Brasiliense, 2001.

GARDNER, H. As artes e o desenvolvimento humano. Porto Alegre: Artmed, 1997.

GIL, A. C. Como elaborar projetos de pesquisa. 3. ed. São Paulo: Atlas, 1991.

LAKATOS, E. M.; MARCONI, M. de A. Fundamentos de metodologia científica. 3. ed. São Paulo: Atlas, 1991.

LIMA, M. C. Monografia: a engenharia da produção acadêmica. 2. ed. São Paulo: Saraiva, 2008.

MINAYO, M. C. de S. O desafio do conhecimento: pesquisa qualitativa em saúde. 2. ed. São Paulo: Hucitec, 1993.

MINAYO, M. C. de S. (Org.). Pesquisa social: teoria, método e criatividade. Petrópolis: Vozes, 1994.

OLIVEIRA, G. F. de.; DANTAS, F. D. C.; FONSECA, P. N. da. O impacto da hospitalização em crianças de 1 a 5 anos de idade. Revista SBPH, Rio de Janeiro, vol. 7, n. 2, p. 37-54. Disponível em:

$<$ http://pepsic.bvs-psi.org.br/ scielo.php/script_sci_serial/pid_1516-0858/lng_en/nrm_iso >. Acesso em: 05 mar. 2010.

QUAKNIN, M-A. Biblioterapia. São Paulo: Loyola, 1996.

SEVERINO, A. J. Metodologia do trabalho científico. 23. ed. São Paulo: Cortez, 2007. 